\title{
Are patients with COPD psychologically distressed?
}

\author{
E.J. Wagena*, W.A. Arrindell ${ }^{\#}$, E.F.M. Wouters ${ }^{\Uparrow}$ and C.P. van Schayck ${ }^{+}$
}

ABSTRACT: This study was designed to assess the level of psychological distress in a heterogeneous group of patients with chronic obstructive pulmonary disease (COPD), and compare them with the general population and psychiatric outpatients.

A total of 118 patients with COPD, a random sample of 500 subjects from the general population and $\mathbf{5 0 0}$ psychiatric outpatients participated in this study. The Dutch version of the Symptom Checklist-90-Revised was used to assess general psychological distress.

The sample of patients with COPD experienced significantly more psychological distress than the general population and significantly less than psychiatric outpatients. Furthermore, no significant association was found between the severity of the pulmonary disease and the level of psychological distress, although patients with severe or very severe COPD appeared to be at increased risk of depression. Lastly, the pattern of psychological complaints seems comparable in depressed patients with COPD and psychiatric outpatients. Once patients with COPD report suffering from depressive symptoms, the level of distress seems to increase to that found in psychiatric outpatients.

In conclusion, in clinical settings in which psychological complaints are not routinely assessed, the Beck Depression Inventory and Symptom Checklist-90-Revised are very useful for drawing attention to depression and psychological distress.

KEYWORDS: Chronic obstructive pulmonary disease, depression, psychological distress, psychoneuroticism, Symptom Checklist-90-Revised

hronic obstructive pulmonary disease (COPD) is a highly incapacitating health problem and can disturb various aspects of a patient's life. The ability to function in day-today life, as well as the quality of life of a patient with COPD, may be further complicated by psychological complaints or even a concurrent mental disorder. Although the physical illness itself probably contributes to the occurrence and severity of the psychological complaints, this does not mean that these complaints will be resolved once the respiratory complaints are treated. Indeed, in daily practice, the presence of psychological complaints or mental disorders in patients with COPD is often regarded as a complication caused by the physical complaints [1]. As a result, they are regularly overlooked, often remain undiagnosed and are rarely treated $[1,2]$.

Most of the published research on psychological complaints and COPD has addressed the relationship between depression or depressive symptoms and COPD. However, it remains to be investigated whether patients with COPD are at an increased risk of depression compared with controls. In their review, VAN EDE et al. [3] concluded that the empirical evidence for a significant risk of depression in patients with COPD remains inconclusive, mainly as a result of the poor methodological quality of most of the published studies, the absence of a control group and small sample sizes. Since the publication of the review of VAN EDE et al. [3], further studies (e.g. those of LACASSE et al. [4], DAHLÉN and JANSON [5], PeruzZa et al. [6], Yohannes and co-workers [7, 8], DowsOn et al. [9], STAGE et al. [10], VAN MANEN et al. [11], AYDIN and UluşAHIN [13], and AGHANWA and ERHABOR [12]) have addressed the prevalence of depression in patients with COPD. However, relatively few studies have evaluated whether patients with COPD are at an increased risk of depression compared with a control group (consisting of healthy subjects $[6,11,12]$, patients with tuberculosis [13] and/or hypertensive patients [12]). Furthermore, in only one of these studies did the group of COPD patients as well as the control group(s) each consist of $>60$ subjects [11].

It is unlikely that depression is the only mental disorder that has a significant impact on the quality of life of patients with COPD. Research
AFFILIATIONS

*Pulmonary Rehabilitation Centre Hornerheide, Horn, and

"Dept of Respiratory Medicine, and ${ }^{+}$Care and Public Health Research Institute (CAPHRI), University Hospital Maastricht, Maastricht, and \#Heymans Institute, University of Groningen, Groningen, The Netherlands.

\section{CORRESPONDENCE}

E.J. Wagena

A Plein 10

8011 TK Zwolle

The Netherlands

Fax: 31294410571

E-mail: edwin.wagena@solvay.com

Received:

January 262004

Accepted after revision:

February 022005

SUPPORT STATEMENT

This study was supported by grants from the Dutch Asthma Foundation (NAF grant no. 3.2.00.21) and the Health Research and Development Council (ZorgOnderzoek Nederland grant no. 2200.0111), The Netherlands. 
seems to indicate, for instance, that the prevalence of anxiety disorders, particularly generalised anxiety disorder and panic disorder, is higher in patients with COPD than in the general population [14]. Not surprisingly, anxiety too can have a significant and negative impact on the quality of life of patients with COPD, and might be associated with greater disability and impaired functional status [14]. Nonetheless, most of the studies on anxiety and COPD have also had major drawbacks, such as the absence of a control group and small sample sizes [14]. Research on the presence and severity of other mental disorders in patients with COPD is lacking.

The aim of the present study was to determine the level of psychological distress in a heterogeneous sample of patients with COPD. As previously stated, most of the studies in which the presence of psychological complaints and mental disorders in patients with COPD was compared with that in a control group used healthy subjects as the control group. In order to assess the severity of existing psychological problems in patients with COPD, the present authors believe that a healthy control group is insufficient. First, patients with COPD were therefore compared not only with a random sample of the general population, but also with a random sample of psychiatric outpatients. Secondly, in order to assess the association between the severity of the obstruction and psychological distress or depression, the patients with mildto-moderate COPD were compared with those patients classified as suffering from severe-to-very severe COPD. Finally, the depressed COPD patients were separated from the nondepressed, and the former group was compared with the psychiatric outpatients.

\section{METHODS \\ Selection of patients with chronic obstructive pulmonary disease}

For this study, outpatients as well as inpatients with COPD were recruited. Participants were recruited from the general public and from the Pulmonary Rehabilitation Centre Hornerheide, the Netherlands. All participants were recruited from the same province (Limburg) in the south of The Netherlands and provided written informed consent. The diagnosis of COPD was based on the definition provided by the Global Initiative for Chronic Obstructive Lung Disease (GOLD) [15, 16]. For this study, patients with a forced expiratory volume in one second (FEV1) reversibility of $>12 \%$ of the predicted value were excluded. Furthermore, all participants had to have a smoking history of $\geqslant 5 \mathrm{yrs}$. In order to balance for disease severity, the inclusion of patients was stratified according to GOLD staging.

Inhalation of bronchodilators was withheld for $\geqslant 12 \mathrm{~h}$ before pulmonary function was tested. Spirometry was performed using a flow screen (Masterlab; Jaeger, Würzburg, Germany) before and $20 \mathrm{~min}$ after inhalation of $400 \mu \mathrm{g}$ salbutamol, using a metered-dose inhaler with a spacer device. FEV1 and forced vital capacity (FVC) were calculated from the flow-volume curve. The highest value of at least three acceptable assessments was used in the analysis.

Selection of general population and psychiatric outpatients For the Dutch version of the Symptom Checklist-90-Revised (SCL-90-R), ARRINDELL and ETTEMA [17] collected data from different Dutch reference groups. From both the general population $(n=2,394)$ and psychiatric outpatient reference $(n=5,748)$ groups, 500 respondents who did not have any missing values for the total scores for the different subscales of the SCL-90-R were randomly selected. Both random samples were stratified according to age and sex, in order to create groups that were comparable, as regards these variables, to the present group of patients with COPD.

\section{Measurements}

For the measurement of general psychological distress, the Dutch version of the SCL-90-R was used [17]. The SCL-90-R is a 90-item self-reported symptom inventory that is designed to screen for a broad range of psychological complaints [18]. Each of the 90 items is rated on a five-point Likert-type scale, ranging from "not at all" (1) to "extremely" (5) for indication of the severity of symptoms over the past week. Subsequently, the answers are combined in eight primary symptom dimensions: phobic anxiety (d1); general anxiety (d2); depression (d3); hostility (d4); inadequacy of thought and action (d5); interpersonal sensitivity and paranoid ideation (d6); sleeping problems (d7); and somatisation (d8). The total score is used to assess the level of general psychological distress. Although the SCL-90-R was originally developed for psychiatric outpatients, it has been used in several settings (e.g. primary care, general population and chronic pain patients), and has proved to have good-to-excellent psychometric properties [17].

Since clinical cut-off scores for the subscales of the SCL90-R are not available, the SCL-90-R cannot be used to assess the presence of a psychological illness (e.g. depression). Therefore, the Beck Depression Inventory (BDI) was used to assess the presence of depression [19]. In accordance with BECK et al. [19], a cut-off score of 15 was used for the BDI, in order to separate the patients with no or mild depression (BDI <15) from those with moderate-to-severe depression (BDI $\geqslant 15$ ). The BDI is based on clinical observations, which were consolidated systematically into 21 symptoms and attitudes that can be rated 0-3 in terms of intensity [19]. The items were chosen to assess the intensity of depression [19]. In patients with missing data for three or less of the 21 items of the BDI, the missing data were replaced by the mean values of the valid data.

Age and body mass index (expressed in $\mathrm{kg} \cdot \mathrm{m}^{-2}$ ) were also assessed in each patient with COPD.

\section{Statistical analysis}

Descriptive statistics were computed for each of the variables analysed. Results are presented as mean $\pm \mathrm{SD}$. In order to compare the different groups stratified by age and sex, the independent-samples t-test and Chi-squared test were used. Since the SCL-90-R has never been used in patients with COPD, the internal consistency (Cronbach's $\alpha$-coefficient [20]) of the subscales of the SCL-90-R was assessed [17]. The size of Cronbach's $\alpha$-coefficient reflects the reliability of the scale. $\alpha$ Coefficients of $<0.70$ were considered unacceptably low, those of $0.70-0.79$ reasonable and those of $\geqslant 0.80$ good-to-excellent [21]. Furthermore, the homogeneity of the subscales was assessed by calculating the mean inter-item correlation separately for every subscale. Homogeneity refers to the statistical coherence of the scale items, and is assumed to be 
optimal if the mean inter-item correlation lies in the range $0.20-0.40$ [22]. High mean inter-item correlations $(>0.70)$ could indicate redundancy of some of the items. The prevalence of depression was determined by estimating the percentage of patients with a score of $\geqslant 15$ on the BDI. The observations on the subscales of the SCL-90-R within the general population and patients with COPD were not normally distributed. In order to compare the scores on the subscales of the SCL-90-R, the nonparametric Mann-Whitney U-test was used. The critical value of $\alpha$ was set at 0.01 .

\section{RESULTS \\ Patient characteristics}

A total of 197 subjects gave oral consent to participation in the present study. In total, 75 subjects were excluded on the basis of an FEV1/FVC ratio of $>0.7$. A further four subjects were excluded because their FEV1 reversibility was $>12 \%$ pred. For the present study, data from 118 patients with COPD were used. The demographic and clinical characteristics of the study population are shown in table 1 . Results indicate that almost $30 \%$ of the included patients $(n=35)$ had a score of $\geqslant 15$ on the BDI, indicating moderate-to-severe depression.

\section{Internal consistency of questionnaires}

Table 2 presents Cronbach's $\alpha$-coefficients for the subscales of the SCL-90-R. The $\alpha$-coefficients range $0.62-0.94$. The internal consistency of the SCL-90-R subscales, except for the hostility scale, which was rather low $(\alpha=0.62)$, was good-to-excellent. Since Cronbach's $\alpha$-coefficient also depends on the number of items, and the homogeneity of the hostility scale was 0.25 , it can be concluded that this subscale of the SCL-90-R was reliable. The mean inter-item correlations of the other SCL-90-R subscales ranged $0.36-0.62$, indicating appropriate item homogeneity.

\begin{tabular}{lc} 
TABLE 1 & $\begin{array}{l}\text { Demographic and clinical characteristics of } \\
\text { selected patients with chronic obstructive } \\
\text { pulmonary disease (COPD) }\end{array}$ \\
& COPD \\
\hline Subjects $\mathbf{n}$ & 118 \\
Age yrs & $57.5 \pm 9.0$ \\
Males & $65(55)$ \\
BMI kg $\cdot \mathbf{m}^{-\mathbf{2}}$ & $24.4 \pm 4.8$ \\
Post-bronchodilator FEV $\mathbf{1}$ \% pred & $56.0 \pm 27.2$ \\
FEV1/FVC ratio & $0.47 \pm 0.14$ \\
GOLD COPD stage & \\
$\quad$ Mild & $28(23.7)$ \\
Moderate & $30(25.4)$ \\
$\quad$ Severe & $38(32.2)$ \\
$\quad$ Very severe & $22(18.6)$ \\
BDI $\geqslant \mathbf{1 5}$ & $35(29.7)$ \\
\hline
\end{tabular}

Data are presented as $n$, mean \pm SD and $n(\%)$. BMl: body mass index; FEV1: forced expiratory volume in one second; \% pred: percentage of the predicted value; FVC: forced vital capacity; GOLD: Global Initiative for Chronic Obstructive Lung Disease; BDI: Beck Depression Inventory.

\begin{tabular}{|c|c|c|c|c|}
\hline \multirow{2}{*}{$\begin{array}{l}\text { TABLE } 2 \\
\text { SCL-90-R }\end{array}$} & \multicolumn{4}{|c|}{$\begin{array}{l}\text { Internal consistencies of Symptom Checklist-90- } \\
\text { Revised (SCL-90-R) subscales in patients with } \\
\text { chronic obstructive pulmonary disease }\end{array}$} \\
\hline & & Items $\mathbf{n}$ & $\begin{array}{l}\text { Cronbach's } \\
\alpha \text {-coefficient }\end{array}$ & Homogeneity" \\
\hline \multicolumn{2}{|c|}{ Phobic anxiety (7-35) } & 7 & 0.86 & 0.48 \\
\hline \multicolumn{2}{|c|}{ General anxiety (10-50) } & 10 & 0.92 & 0.52 \\
\hline \multicolumn{2}{|c|}{ Depression (16-80) } & 16 & 0.94 & 0.51 \\
\hline \multicolumn{2}{|c|}{ Hostility (6-30) } & 6 & 0.62 & 0.25 \\
\hline \multicolumn{2}{|c|}{$\begin{array}{l}\text { Inadequacy of thought and } \\
\text { action (9-45) }\end{array}$} & 9 & 0.88 & 0.45 \\
\hline \multicolumn{2}{|c|}{$\begin{array}{c}\text { Interpersonal sensitivity and } \\
\text { paranoid ideation (18-90) }\end{array}$} & 18 & 0.94 & 0.45 \\
\hline \multicolumn{2}{|c|}{ Sleeping problems (3-15) } & 3 & 0.83 & 0.62 \\
\hline \multicolumn{2}{|c|}{ Somatisation (12-60) } & 12 & 0.87 & 0.36 \\
\hline
\end{tabular}

\section{Psychological distress and depression in patients with chronic obstructive pulmonary disease}

As the random samples of the general population and psychiatric outpatients were stratified according to age and sex, the sample of patients with COPD did not differ from the general population $(t=-1.214$, degrees of freedom $(d f)=620$, $\mathrm{p}=0.71)$ or psychiatric outpatient $(\mathrm{t}=-0.377, \mathrm{df}=154, \mathrm{p}=0.23)$ groups on the basis of age, or on the basis of $\operatorname{sex}\left(\chi^{2}=0.66\right.$, $\mathrm{p}=0.42$ ). The mean \pm SD age of the general population sample was $56.4 \pm 9.1$ yrs. The age of the psychiatric outpatients was $57.1 \pm 9.0$ yrs. Both groups consisted of 250 males and 250 females.

Table 3 shows the scores for the subscales of the SCL-90-R in patients with COPD, the general population and psychiatric outpatients. The higher the score, the more symptoms of psychological distress were reported. Patients with COPD scored significantly more highly on all subscales of the SCL-90$\mathrm{R}$ compared with the general population ( $\mathrm{p} \leqslant 0.01$ for all) and significantly less than psychiatric outpatients ( $p \leqslant 0.01$ for all). Thus, patients with COPD reported significantly more psychological complaints than the general population and significantly less than psychiatric outpatients.

As ARRINDELl and ETTEMA [17] point out, in general, females report more psychological distress than males, with the differences reflecting small-to-negligible effect sizes. In other words, females scored slightly more highly on all subscales of the SCL-90-R than males. Although the present results support this general finding, no significant difference was found for any of the subscales between male and female patients with COPD ( $p>0.01$ for all). The same trend was found for the BDI. The prevalence of moderate-to-severe depression was higher in females than in males (36 versus $25 \%$ ) and seems clinically relevant, although the difference was not significant $\left(\chi^{2}=1.78\right.$, $\mathrm{df}=1, \mathrm{p}=0.18)$.

Table 4 presents the prevalence of depression in patients with mild-to-moderate and severe-to-very severe COPD. Although 


\begin{tabular}{|c|c|c|c|c|}
\hline \multirow[t]{2}{*}{ TABLE 3} & \multicolumn{4}{|c|}{$\begin{array}{l}\text { Psychological distress in patients with chronic } \\
\text { obstructive pulmonary disease (COPD), the } \\
\text { general population and psychiatric outpatients }\end{array}$} \\
\hline & & $\begin{array}{l}\text { General Dutch } \\
\text { population }\end{array}$ & $\begin{array}{c}\text { COPD } \\
\text { patients }\end{array}$ & $\begin{array}{l}\text { Psychiatric } \\
\text { outpatients }\end{array}$ \\
\hline \multicolumn{2}{|c|}{$\begin{array}{l}\text { Subjects n } \\
\text { SCL-90-R subscale } \\
\text { score }\end{array}$} & 500 & 118 & 500 \\
\hline \multicolumn{2}{|c|}{ Phobic anxiety } & $7.9 \pm 2.2$ & $10.0 \pm 4.6$ & $13.5 \pm 7.3$ \\
\hline \multicolumn{2}{|c|}{ General anxiety } & $12.9 \pm 4.9$ & $17.2 \pm 7.7$ & $24.8 \pm 9.6$ \\
\hline \multicolumn{2}{|c|}{ Depression } & $21.5 \pm 7.3$ & $30.8 \pm 13.7$ & $42.4 \pm 14.1$ \\
\hline \multicolumn{2}{|l|}{ Hostility } & $7.0 \pm 1.9$ & $7.7 \pm 2.1$ & $10.2 \pm 4.1$ \\
\hline \multicolumn{2}{|c|}{$\begin{array}{l}\text { Inadequacy of } \\
\text { thought and } \\
\text { action }\end{array}$} & $13.1 \pm 4.5$ & $17.4 \pm 6.6$ & $21.7 \pm 7.9$ \\
\hline \multicolumn{2}{|c|}{$\begin{array}{l}\text { Interpersonal sensi- } \\
\text { tivity and paranoid } \\
\text { ideation }\end{array}$} & $23.8 \pm 7.4$ & $27.4 \pm 10.8$ & $35.4 \pm 13.1$ \\
\hline \multicolumn{2}{|c|}{ Sleeping problems } & $4.9 \pm 2.6$ & $7.1 \pm 3.5$ & $8.5 \pm 3.9$ \\
\hline \multicolumn{2}{|c|}{ Somatisation } & $17.3 \pm 5.9$ & $23.2 \pm 8.0$ & $26.1 \pm 9.9$ \\
\hline \multicolumn{2}{|c|}{$\begin{array}{l}\text { General psychological } \\
\text { distress }^{\#}\end{array}$} & $119.4 \pm 33.4$ & $153.7 \pm 53.7$ & $199.0 \pm 59.4$ \\
\hline
\end{tabular}

Data are presented as $\mathrm{n}$ and mean $\pm \mathrm{SD}$. SCL-90-R: Symptom Checklist-90Revised. \#: total score.

\begin{tabular}{|c|c|c|c|}
\hline \multirow[t]{2}{*}{ TABLE 4} & \multicolumn{3}{|c|}{$\begin{array}{l}\text { Psychological distress and prevalence of } \\
\text { depression in patients with chronic obstructive } \\
\text { pulmonary disease (COPD), grouped according to } \\
\text { Global Initiative for Chronic Obstructive Lung } \\
\text { Disease staging }\end{array}$} \\
\hline & & $\begin{array}{l}\text { Mild-to-moderate } \\
\text { COPD }\end{array}$ & $\begin{array}{c}\text { Severe-to-very } \\
\text { severe COPD }\end{array}$ \\
\hline Subjects $\mathbf{n}$ & & 58 & 60 \\
\hline Age yrs & & $54.9 \pm 7.7$ & $60.0 \pm 9.6$ \\
\hline Males & & $32(55)$ & $33(55)$ \\
\hline BDI $\geqslant 15$ & & $13(22)$ & $22(37)$ \\
\hline \multicolumn{4}{|c|}{ SCL-90-R subscale score } \\
\hline \multicolumn{2}{|c|}{ Phobic anxiety } & $9.7 \pm 4.3$ & $10.4 \pm 4.9$ \\
\hline \multicolumn{2}{|c|}{ General anxiety } & $17.2 \pm 8.2$ & $17.3 \pm 7.3$ \\
\hline \multicolumn{2}{|l|}{ Depression } & $30.3 \pm 14.1$ & $31.3 \pm 13.4$ \\
\hline \multicolumn{2}{|l|}{ Hostility } & $7.9 \pm 2.3$ & $7.5 \pm 1.9$ \\
\hline \multicolumn{2}{|c|}{$\begin{array}{l}\text { Inadequacy of thought and } \\
\text { action }\end{array}$} & $16.6 \pm 6.2$ & $18.1 \pm 7.0$ \\
\hline \multicolumn{2}{|c|}{$\begin{array}{l}\text { Interpersonal sensitivity and } \\
\text { paranoid ideation }\end{array}$} & $27.9 \pm 10.6$ & $26.8 \pm 11.1$ \\
\hline \multicolumn{2}{|c|}{ Sleeping problems } & $6.9 \pm 3.2$ & $7.2 \pm 3.7$ \\
\hline \multicolumn{2}{|c|}{ Somatisation } & $23.4 \pm 8.0$ & $23.1 \pm 8.0$ \\
\hline \multicolumn{2}{|c|}{ General psychological distress $\#$} & $153.0 \pm 55.2$ & $154.4 \pm 52.6$ \\
\hline
\end{tabular}

Data are presented as $n$, mean \pm SD and $n$ (\%).BDI: Beck Depression Inventory; SCL-90-R: Symptom Checklist-90-Revised. \#: total score.

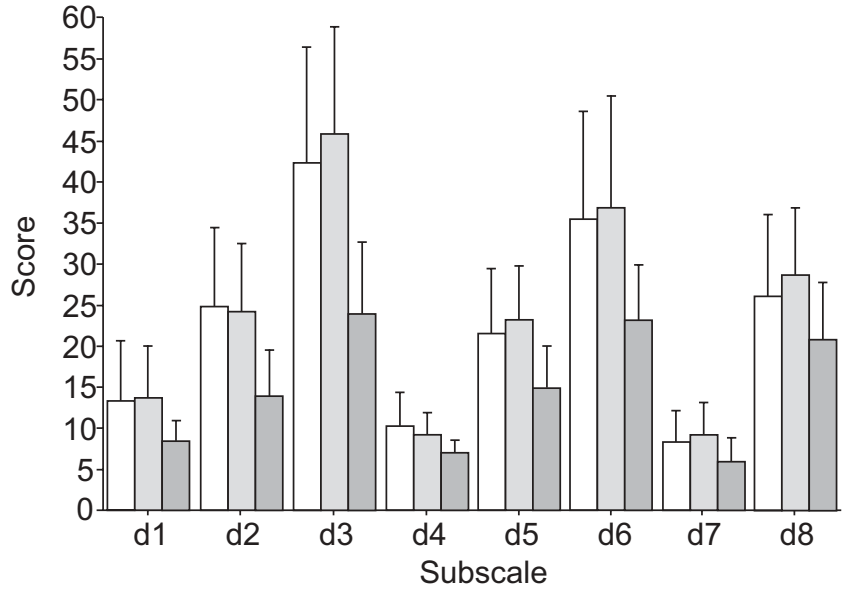

FIGURE 1. Symptom Checklist-90-Revised subscale (d1: phobic anxiety, d2: general anxiety, d3: depression, d4: hostility, d5: inadequacy of thought and action, d6: interpersonal sensitivity and paranoid ideation, d7: sleeping problems, d8: somatisation) scores in psychiatric outpatients $(\square)$ and depressed ( $\square$ ) and nondepressed $(\square)$ patients with chronic obstructive pulmonary disease. Data are presented as mean $\pm \mathrm{SD}$.

a higher percentage of patients with severe or very severe COPD reported suffering from moderate-to-severe depression compared with patients with mild or moderate COPD (37 versus $22 \%)$, this difference was not significant $\left(\chi^{2}=2.87\right.$, $\mathrm{p}=0.09$ ). The same table shows that no difference was detected in general psychological distress between patients with COPD stage I or II and those with stage III or IV ( $p>0.05$ for all).

Figure 1 shows the mean SCL-90-R subscale scores for depressed and nondepressed patients with COPD and psychiatric outpatients. Depressed patients with COPD (BDI $\geqslant 15$ ) had significantly worse scores (higher means) for all subscales of the SCL-90-R than those patients with no depression (BDI $<15 ; \mathrm{p}<0.01$ for all). However, when the group of depressed COPD patients was compared with the psychiatric outpatients, no significant differences could be found on any of the subscales of the SCL-90-R. These results indicate that the pattern of psychological complaints (i.e. mean SCL-90-R subscale scores) was comparable in depressed patients with COPD and psychiatric outpatients. Furthermore, the depressed patients with COPD experienced significantly more general distress than the psychiatric outpatients (SCL-90-R total scores of 205.1 and 199.0, respectively; $\mathrm{p}<0.01$ ). It is, however, also questionable whether this difference is clinically relevant.

\section{DISCUSSION}

The present study specifically set out to determine the level of psychological distress in a heterogeneous group of patients with COPD as compared with the general population and psychiatric outpatients using the SCL-90-R. Although a large body of evidence has shown that the subscales of the SCL-90-R are valid and stable in different groups (e.g. general population, primary care population and psychiatric outpatients) [17], no study could be found in which the SCL-90-R was used in patients with COPD. The reliability analyses performed in the present study show that the SCL-90-R is a reliable instrument 
for measuring the level of psychological distress in patients with COPD.

The present sample of patients with COPD experienced markedly more psychological distress than a random sample from the general Dutch population. At the same time, patients with COPD scored significantly less on the subscales of the SCL-90-R than psychiatric outpatients. In daily practice, it is often assumed that the physical illness itself contributes to the occurrence and severity of mental disorders [1]. It was, therefore, assessed whether the level of psychological distress is associated with the severity of the pulmonary obstruction. No significant increase in psychological complaints was found in patients with severe or very severe COPD compared to patients with mild or moderate COPD. There does not seem to be a significant or clinically relevant difference in psychological distress between patients with severe or very severe COPD and patients with mild or moderate COPD. However, since the SCL-90-R cannot be used to identify cases (it is designed to screen for a broad range of psychological complaints), this lack of a significant difference in psychological distress between patients with severe or very severe COPD compared to patients with mild or moderate COPD does not mean that the number of patients with a mental disorder is also comparable between the groups.

In the present study, the prevalence of depression (assessed using the BDI) in patients with severe or very severe COPD was $37 \%$ compared with $22 \%$ in patients with mild or moderate COPD. Although this difference was rather large, it failed to reach significance. It could very well be that the difference found is clinically relevant as the sample size of patients with COPD might not have been sufficient to detect a significant difference. Only one other study could be identified in which the prevalence of depression in severe COPD patients was compared with that found in patients with mild or moderate COPD [11]. VAN MANEN et al. [11] also found that patients with severe airways obstruction were at an increased risk of depression (25 versus 20\%), although the difference between these groups was much less. These authors also failed to find a significant difference in prevalence rates. This variation in prevalence rates might have been caused by the use of different measures for depression.

Finally, the level of psychological distress in depressed COPD patients was compared with that found in psychiatric outpatients. On all subscales of the SCL-90-R, no difference was detected between depressed patients with COPD and psychiatric outpatients. Although depressed patients with COPD experienced significantly more general distress (as assessed by the total SCL-90-R score) than psychiatric outpatients, this difference was very small and most probably not clinically relevant. Although the absence of significant differences does not imply clinical comparability or equivalence [23], the level of psychological distress experienced, as assessed by the subscales of the SCL-90-R, seems to be similar in both groups. In other words, depressed patients with COPD seem to experience the same pattern of psychological complaints as psychiatric outpatients. Do these results mean that depressed patients with COPD are also more likely than the general population to suffer from mental disorders (e.g. anxiety, depression and somatisation)? Furthermore, is the level of these disorders in depressed patients with COPD comparable to that found in psychiatric outpatients? Although the SCL-90-R cannot be used to assess the presence of mental disorders, the results of the present study support these suppositions. Earlier research seems to indicate, for instance, that patients with COPD not only are at an increased risk of anxiety [14], but also frequently have problems with sleeping [24]. Sleep in patients with COPD is characterised by longer latency to sleep onset, more frequent arousals and awakenings, more frequent stage changes and poorer sleep efficiency compared with healthy individuals [24]. Although these problems are often not severe enough to warrant a diagnosis of insomnia, they still have an impact on the person's physical and mental well-being, as well as on their ability to carry out everyday work and social activities [25]. Furthermore, many people with depression also report difficulties with sleeping [25].

A number of limitations of the present study need to be mentioned. First, since a cross-sectional design was used, only associations can be assessed, and causal inferences cannot be drawn. This means that it could not be established whether the physical illness itself causes the occurrence and severity of the psychological complaints. Secondly, all measures were self-reported. In order to determine the presence of depression and the level of psychological distress, patients were asked to answer the questions of the BDI and the SCL-90-R. As a consequence of this, clinical diagnoses of major depression or other mental disorder could not be formally made. The third limitation pertains to the external validity of the results. Ideally, the present group of COPD patients, as well as both reference groups, should be random samples of the corresponding Dutch groups. Although the inclusion of patients with COPD was balanced for disease severity, it is not known whether this sample is representative of the Dutch population of COPD patients. In addition, the patients who participated in this study lived in the same southern province (Limburg) of The Netherlands. However, attempts were made to maximise the external validity of the present study by selecting COPD patients with varying disease severity. Furthermore, since 500 respondents were randomly selected from both the general population and the psychiatric outpatient reference groups, who did not have any missing values for the total scores of the different subscales of the SCL-90-R, nonrandom selection might have been introduced. It could be argued that, in general, respondents who suffer from specific complaints do not want to answer questions relating to these complaints. If this is true, the present random samples might underestimate the true level of psychological distress in both groups. However, the opposite possibility cannot be ruled out. Finally, as the data from the psychiatric outpatient reference group were collected between 1989 and 2002 , time could have introduced bias. The way in which the general population, as well as health professionals, think about depression and depressive disorder might well have changed during these 13 yrs. However, ARRINDELL and ETTEMA [17] did not find any systematic differences between the patients who had answered the questions of the SCL-90-R between 1989 and 1995 and those who did so between 1995 and 2002. 
In conclusion, the present study showed significantly higher levels of psychological distress in patients with COPD compared with the general population, although their scores were significantly lower than those of psychiatric outpatients. Furthermore, no significant increase was found in psychological complaints in patients with severe or very severe COPD compared with patients with mild or moderate COPD, although the prevalence of depressive disorder seems to be higher in the more severe COPD patients. When the level of psychological distress is assessed separately in depressed and nondepressed patients with COPD, it is striking that the level of psychological distress in depressed COPD patients seems to be comparable to that found in psychiatric outpatients. Patients with COPD seem to be at increased risk of not only depression, but also other mental disorders. In spite of their enormous clinical and public health importance, the presence of psychological disorders is often underdiagnosed and undertreated [26], particularly when these disorders coexist with physical illness $[1,2]$.

The present authors believe that medical practitioners should be able to recognise the clues and symptoms that could indicate the presence of a psychological disorder. Physicians should be aware that persistent low mood and lack of interest and pleasure in life cannot be accounted for by severe physical illness alone [1]. Although the use of self-reporting questionnaires, such as the Beck Depression Inventory and Symptom Checklist-90-Revised, cannot replace systematic clinical assessment, these instruments are very useful in drawing attention to depression and psychological distress in clinical settings in which psychological complaints are not routinely assessed. Milder complaints can be managed by primary and secondary care staff without recourse to specialist referral. However, it is important that healthcare staff are familiar with the properties and use of the more common antidepressant drugs, as well as the value of brief psychological treatments, such as problem solving, education and reassurance about common reactions to the threats and losses associated with COPD, and approaches that support or promote active coping strategies. Patients with more enduring or severe symptoms usually require specific forms of therapy (e.g. drug treatment and cognitive behavioural psychotherapies) [1].

\section{ACKNOWLEDGEMENTS}

The authors would like to thank P. Knipschild for comments on earlier drafts of this manuscript.

\section{REFERENCES}

1 Peveler R, Carson A, Rodin G. ABC of psychological medicine. Depression in medical patients. BMJ 2002; 325: 149-152.

2 Spitzer RL, Williams JBW, Kroenke K, et al. Utility of a new procedure for diagnosing mental disorders in primary care. JAMA 1994; 272: 1749-1756.

3 Van Ede L, Yzermans CJ, Brouwer HJ. Prevalence of depression in patients with chronic obstructive pulmonary disease: a systematic review. Thorax 1999; 54: 688-692.

4 Lacasse Y, Rousseau L, Maltais F. Prevalence of depressive symptoms and depression in patients with severe oxygendependent chronic obstructive pulmonary disease. J Cardiopulm Rehabil 2001; 20: 80-86.
5 Dahlén I, Janson C. Anxiety and depression are related to the outcome of emergency treatment in patients with obstructive pulmonary disease. Chest 2002; 122: 1633-1637.

6 Peruzza S, Sergi G, Vianello A, et al. Chronic obstructive pulmonary disease (COPD) in elderly subjects: impact on functional status and quality of life. Respir Med 2003; 97: 612-617.

7 Yohannes AM, Baldwin RC, Connolly MJ. Depression and anxiety in elderly outpatients with chronic obstructive pulmonary disease: prevalence, and validation of the BASDEC screening questionnaire. Int J Geriatr Psychiatry 2000; 15: 1090-1096.

8 Yohannes AM, Baldwin RC, Connolly MJ. Prevalence of sub-threshold depression in elderly patients with chronic obstructive pulmonary disease. Int J Geriatr Psychiatry 2003; 18: 412-416.

9 Dowson C, Laing R, Barraclough R, et al. The use of the Hospital Anxiety and Depression Scale (HADS) in patients with chronic obstructive pulmonary disease: a pilot study. N Z Med J 2001; 114: 447-449.

10 Stage KB, Middelboe T, Pisinger C. Measurement of depression in patients with chronic obstructive pulmonary disease (COPD). Nord J Psychiatry 2003; 57: 297301.

11 Van Manen JG, Bindels PJ, Dekker FW, Ijzermans CJ, van der Zee JS, Schadé E. Risk of depression in patients with chronic obstructive pulmonary disease and its determinants. Thorax 2002; 57: 412-416.

12 Aghanwa HS, Erhabor GE. Specific psychiatric morbidity among patients with chronic obstructive pulmonary disease in a Nigerian general hospital. I Psychosom Res 2001; 50: 179-183.

13 Aydin IO, Uluşahin A. Depression, anxiety comorbidity, and disability in tuberculosis and chronic obstructive pulmonary disease patients: applicability of GHQ-12. Gen Hosp Psychiatry 2001; 23: 77-83.

14 Brenes GA. Anxiety and chronic obstructive pulmonary disease: prevalence, impact, and treatment. Psychosom Med 2003; 65: 963-970.

15 Pauwels RA, Buist AS, Calverley PM, Jenkins CR, Hurd SS. Global strategy for the diagnosis, management, and prevention of chronic obstructive pulmonary disease. NHLBI/WHO Global Initiative for Chronic Obstructive Lung Disease (GOLD) Workshop summary. Am J Respir Crit Care Med 2001; 163: 1256-1276.

16 Fabbri LM, Hurd SS. Global strategy for the diagnosis, management and prevention of COPD: 2003 update. Eur Respir J 2003; 22: 1-2.

17 Arrindell WA, Ettema JHM. SCL-90: Handleiding bij een multidimensionele psychopathologie-indicator [SCL-90: Manual for a multifaceted measure of psychopathology]. Lisse, Swets \& Zeitlinger, 2003.

18 Derogatis LR, Lipman RS, Covi L. SCL-90: an outpatient psychiatric rating scale: preliminary report. Psychopha rmacol Bull 1973; 9: 13-28.

19 Beck AT, Steer RA, Garbin MG. Psychometric properties of the Beck Depression Inventory: twenty-five years of evaluation. Clin Psychol Rev 1988; 8: 77-100.

20 Cronbach L. Coefficient alpha and the internal structure of tests. Psychometrika 1951; 16: 297-334. 
21 Cichetti DV. Guidelines, criteria, and rules of thumb for evaluating normed and standardized assessment instruments in psychology. Psychol Assess 1994; 6: 284290.

22 Briggs SR, Cheek JM. The role of factor analysis in the development and evaluation of personality scales. J Pers 1986; 54: 106-148.

23 Jones B, Jarvis P, Lewis JA, Ebbutt AF. Trials to assess equivalence: the importance of rigorous methods. BMJ 1996; 313: 36-39.
24 George CFP, Bayliff CD. Management of insomnia in patients with chronic obstructive pulmonary disease. Drugs 2003; 63: 379-387.

25 Kupfer DJ. Pathophysiology and management of insomnia during depression. Ann Clin Psychiatry 1999; 11: 267-276.

26 WHO World Mental Health Survey Consortium. Prevalence, severity, and unmet need for treatment of mental disorders in the World Health Organization World Mental Health Surveys. JAMA 2004; 291: 2581-2590. 